\title{
Microfluidic PCR Chips
}

Jingdong Chen ${ }^{1}$, Di Chen ${ }^{1}$, Tao Yuan ${ }^{1}$, Xiang Chen ${ }^{2}$

\author{
${ }^{1}$ National Key Laboratory of Science and Technology on Micro/Nano Fabrication Technology \\ ${ }^{2}$ Key Laboratory for Thin Film and Microfabrication of the Ministry of Education \\ Research Institute of Mico/Nano Science and Technology, Shanghai Jiao Tong University, Shanghai 200240, China \\ * Corresponding author: dchen@sjtu.edu.cn (Di Chen)
}

\begin{abstract}
The microfluidic polymerase chain reaction (PCR) chips have undergone extensive development and nowadays have become an important domain of miniaturization technology application. Here, we review the advances of microfluidic PCR chips over the past years, from the first single chamber stationary PCR chip to the new SlipChip PCR. First, the three distinct types of microfluidic PCR chips are discussed, including chamber stationary PCR chips, flow-through PCR chips and convection PCR chips. Then we focus on droplet PCR chips and SlipChip PCR. Although they are at an early stage, they show the great potential for high-throughput PCR and robust chip. Finally, general discussions on integrated chips are given. The low cost, portable, high-throughout integrated PCR chips will certainly be further developed in spite of many challenges.
\end{abstract}

Keywords: Chamber stationary PCR chip, Flow-through PCR chips, Convection PCR chip, Droplet PCR chip, SlipChip PCR, Integrated PCR chip

Citation: J. Chen et al. Microfluidic PCR chips. Nano Biomed. Eng. 2011, 3(4), 203-210. DOI: 10.5101/nbe.v3i4.p203-210.

\section{Introduction}

Since micro total analysis system ( $\mu$-TAS), also known as "lab-on-a-chip", was proposed in the early 1990s [1], microfluidic chip manufactured by microelectromechanical system (MEMS) technology has been considered as a potential technology to miniaturize the conventional equipments and technologies. Because it offers advantages in terms of small volume, low cost, short reaction time, high throughput. It has already been used in chemical and biological analysis [2,3], cell analysis and clinical diagnostics [4-6] drug discovery [7], and environmental monitoring [8]. Among the microfluidic chips, the polymerase chain reaction (PCR) chip has become a very important tool in modern biology, biomedical research and related areas. The PCR technique was first developed in 1985 [9], and has been widely used as a molecular biological tool to replicate DNA by cycling through three temperature steps. After the first PCR chip was introduced by Northrup et al. [10], many research groups began to study microfluidic PCR chips and developments of microfluidic PCR chips were accelerated.

This review surveys the development of different microfluidic PCR chips. We begin with the three distinct types of microfluidic PCR chips (chamber stationary PCR chips, flow-through PCR chips and thermal convectiondriven PCR chips). Next, we describe droplet PCR chips and SlipChip PCR with the great potential for high- throughput PCR and robust chip. Finally, the potential and challenges about integrated PCR chips are discussed. As a supplement to this review, readers are referred to other reviews about microfluidic technology [11-14].

\section{Types of microfluidic PCR chips}

During the development of microfluidic PCR chips, different types have been developed by many research groups. Currently, the microfluidic PCR chips can be classified into three distinct types: chamber stationary PCR chips, flow-through PCR chips and thermal convection-driven PCR chips.

\subsection{Chamber stationary PCR chip}

The working principle of this type of PCR chip is that the PCR solution is kept stationary and the temperature of the reaction chamber is cycled between three different temperatures. In general, this type of chamber stationary PCR chips can be classified as single chamber [15-17] and multi-chamber [18-20] chips, as shown in Fig.1.

The first PCR chip developed by Northrup et al. [10] was based on a chamber fabricated by silicon anisotropic wet etching, where the PCR solution is kept. Cady et al. [21] constructed the PCR amplification chamber using soft lithography techniques for polydimethylsiloxane (PDMS) and SU-8 photoresist tested for their ability to purify and 


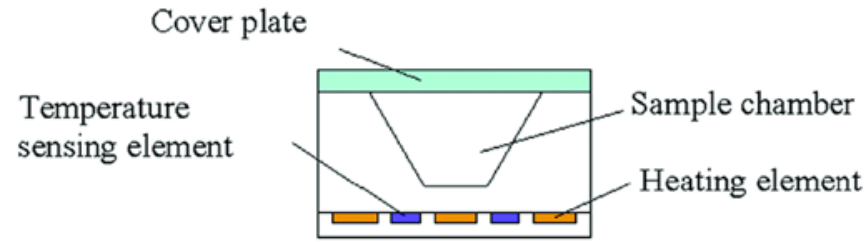

(b)

\section{Cover plate}

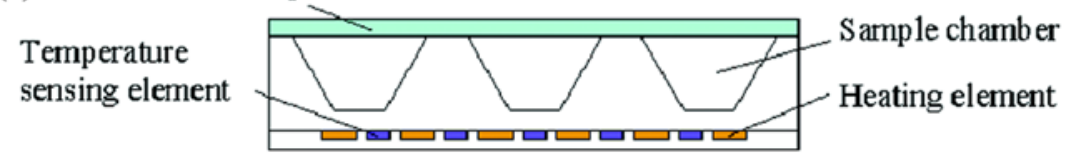

Fig. 1 Chamber stationary PCR chips: (a) Single chamber PCR chip.(.b) Multi-chamber PCR chip [12].

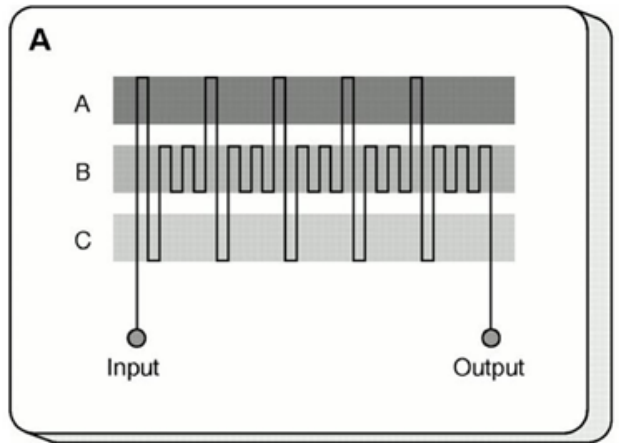

A $\quad 95^{\circ} \mathrm{C}$ - melting
B $\quad 77^{\circ} \mathrm{C}$ - extension
C $\quad 60^{\circ} \mathrm{C}$ - annealing

Fig. 2 Flow-through PCR chip [26].

detect the pathogeneic bacterium Listeria monocytogenes Qiu et al. [22] developed a disposable, plastic microfluidic reactor with relatively large reaction volume (ranging from $10 \mu \mathrm{L}$ to $100 \mu \mathrm{L}$ ) and used doublesided heater to maintain temperature uniformity and a relatively fast temperature ramping rate. The fluidic and thermal controls can be performed very well. However, a single chamber is not suitable for some sequential PCR tests for a quantity of DNA samples. In order to solve this problem, multi-chamber stationary PCR chips was developed. Daniel et al. [23] fabricated some microchambers in silicon by bulk micromachining using anisotropic wet etching and integrated thin film platinum resistors as temperature sensors and heaters to amplify DNA. Multi-chamber PCR chip for multi-target sample amplification for diagnostic purposes was designed and fabricated by Trung et al. [24]. Silicon-based microchamber array was used to realize high-throughput PCR and PCR was completed in 18 min for 40 cycles [25].

The multi-chamber stationary PCR chips can reduce the time for analysis and increase the PCR throughput because it can perform different sequential PCR tests concurrently. However, it is crucial to ensure temperature uniformity between chambers. The whole chip, including the sample, is heated and cooled through specific thermal-cycling temperatures. Therefore, chamber stationary PCR chips

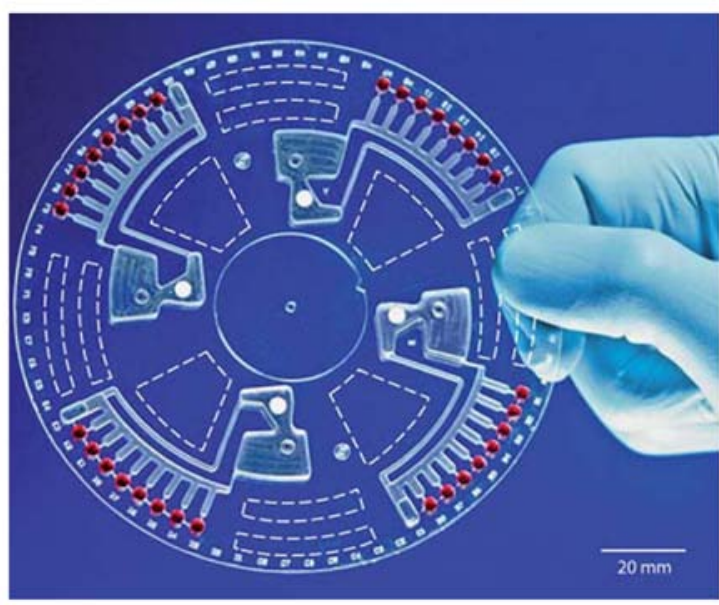

Fig. 3 Photograph of the centrifugal microfluidic chip designed by Focke et al. [33].

have high thermal inertia and long thermal-cycling time.

\subsection{Flow-through PCR chip}

The working principle of this type of PCR chip is that the PCR solution is continuously and repeatedly flowing through three different temperature zones necessary for DNA amplification, as shown in Fig. 2. It takes advantage in term of rapid heat transfer and high potential for further integration. Kopp et al. successfully performed the polymerase chain reaction (PCR) in continuous flow at high speed using a micromachined chemical amplifier was successfully [26]. The device relied on the movement of sample through thermostated temperature zones on a glass microchip. Since then, flow-through PCR chips have undergone substantial improvements. In this chip, the flow control of the PCR solution is a key issue.

\subsubsection{Pressure driven}

Pressure driven is commonly used by many research groups, which control fluid movement with different pressures applied by mechanical pumps or gas pressure. Liu et al. [27] developed a rotary microfluidic device to run the PCR in both spatially and temporally cycled formats. The small sample volume $(12 \mathrm{nl})$ allows low power consumption, reduced reagent costs, and ultimately 


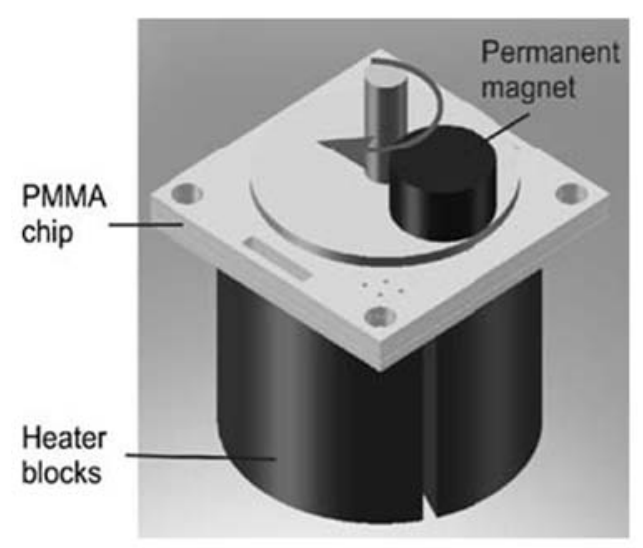

(a)

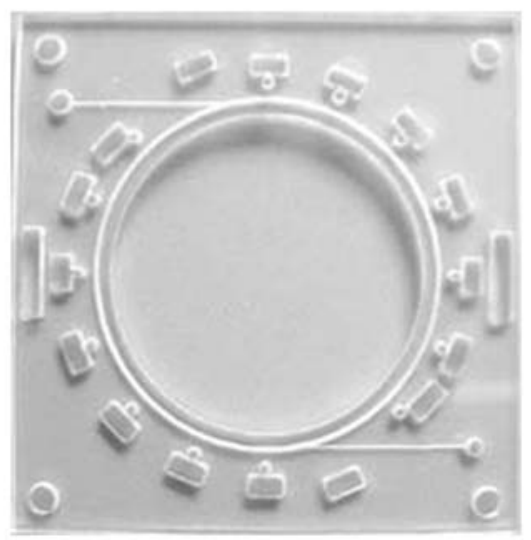

(b)

Fig. 4 (a) Schematic drawing of the PCR microchip with heating blocks and a magnet, (b) Photograph of the PCR chip fabricated in PMMA [35].

more rapid thermal cycling. Wu and Lee [28] proposed a three-dimensional (3D) on-chip continuous-flow PCR, which adopted a single heating source to simplify the temperature control.

\subsubsection{Electrokinetic force driven}

Electrokinetic force driven is another important fluid control technique in microfluidic chips [29]. Patankar and $\mathrm{Hu}$ [30] developed a numerical scheme to simulate electroosmotic flows in complicated geometries and studied the electroosmotic injection characteristics of a cross-channel device for capillary electrophoresis. Gui and Ren [31] proposed a 3D model to simulate the electrical potential field, the flow field, and the temperature field in an electroosmosis-based continuous flow PCR chip.

\subsubsection{Centrifugal force driven}

Centrifugally force driven is an insightful example of the ingenious methods for fluid control which may be used in microfluidic chips. Instead of mechanical or electrokinetic pumps, centrifugal force is used which moves liquids inside circular disks containing all necessary microfluidic components for chemical analysis. Furutani et al. [32] proposed a compact disk (CD)-shaped chip to isolate Salmonella enterica cells and detect the Salmonella- specific invA gene from isolated cells by PCR.The centrifugal force was used to control liquid flow, without a micro-pump. Focke et al. [33] developed a centrifugal microfluidic chip and successfully and realized efficient thermocycling during real-time PCR, as shown in Fig. 3.

\subsubsection{Magnetic field driven}

In this chip, a small ferrofluid plug is controlled by an external magnet, which in turn propels the PCR solution through three temperature zones. Sun et al. [34] presented a novel circular close-loop ferrofluid microfluidic chip for rapid PCR and successfully demonstrated by performing PCR amplification of a $500 \mathrm{bp}$ lambda DNA fragment and a 16-loci forensic DNA sample. Then they amplified the genetically modified soya and maize in less than 13 min for the detection of genetically modified organisms (GMOs) in food products using PCR technology, as shown in Fig. 4 [35].

The high thermal inertia has been dramatically shortened by flow-through PCR chips. However, PCR inhibition and contamination become the major challenges due to high surface/volume ratio [36, 37].

\subsection{Convection PCR chip}

The working principle of convection PCR chip is Rayleigh-Bénard convection, which is caused by buoyancy-driven instability in a confined fluid layer heated. This convection PCR chips consist of two fixed different temperature zones. Buoyancy force is the only force to drive PCR solution flow through the temperature zones.

Krishnan et al. [38] reported a PCR convection system to perform PCR amplification of DNA inside a $35-\mu \mathrm{L}$ cylindrical cavity. The temperature cycling was generated as the flow continuously shuttles fluid vertically through the two temperature zones of denaturation $\left(97^{\circ} \mathrm{C}\right)$ and annealing/extension $\left(61^{\circ} \mathrm{C}\right)$. Yao et al. [39] designed a micro-PCR system that integrated measurement circuits, and circuits to control the temperature. They optimized the stream function, velocity, and temperature profile through simulation and found the minimum reaction duration as a function of the velocity, temperature distribution, and extension time for a specific aspect ratio of the convection cavity. Chung et al. [40] presented a standalone portable convection PCR chip which can conduct multiple PCR in a very short time (about $5 \mathrm{~min}$ ). Natural convection drove PCR reactants to circulate along a closed loop channel in the polymer chip, as shown in Fig. 5. Convection PCR is predicted to be a promising method due to its low cost, simplicity, high speed and low 

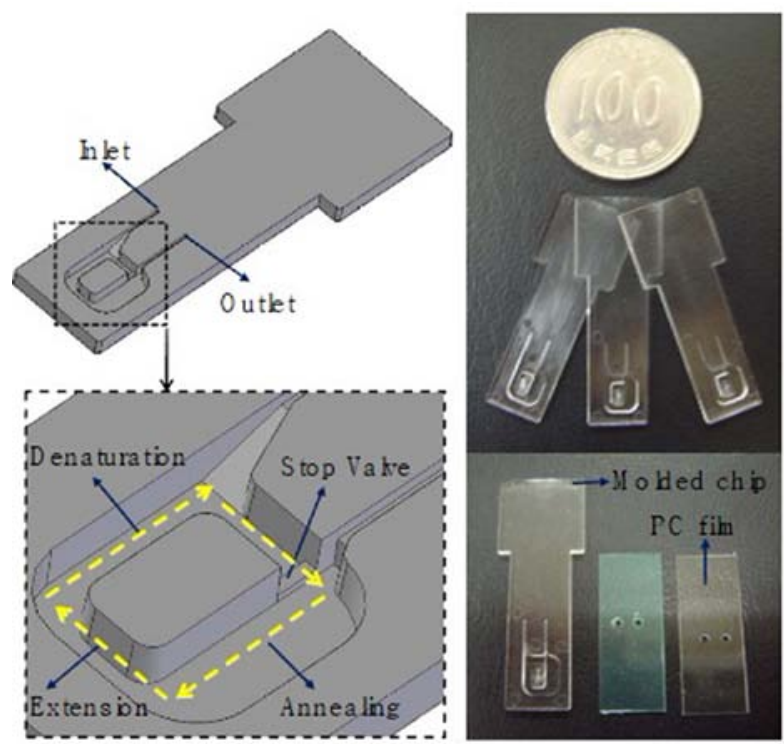

Fig. 5 .Convection PCR chip (a) design, (b) fabrication [40].

power consumption [41, 42]. And challenges still exist in realization of parallel and multiplex convective PCR and integration of convective PCR with other functionalities.

\section{Droplet PCR chip}

In order to prevent PCR inhibition and contamination, some researchers use surface modification method [4345]. Schneegass et al. [43] modified the channel surface with hexamethyldisilazane (HMDS) before the injection of the PCR solution, so the hydrophobic material surface of the silicon/glass was changed to enhance surface biocompatibility. However, this method is not easy to manipulate in the sealed chip. Fortunately, the PCR inhibition and contamination can be overcome by using droplet PCR chip. In general, droplets are typically generated using three main generation strategies: capillary, T-junction and flow focusing, as shown in Fig. 6 [46]. In droplet PCR chip, the PCR solution (water phase) within the droplets are surrounded by an immiscible fluid (oil phase), so the inhibition and contamination result from contact between chambers and the sample is avoid. In addition, The PCR solution contained in droplets can decrease its evaporation, which is a common problem in single-phase chips. Unlike in single-phase chips, each independent droplet in droplet PCR chips likes a microreactor which can be individually transported, split, mixed, sorted and analyzed [46-53].

Pipper et al. [54] used magnetic force to manipulate a free droplet containing superparamagnetic particles to detect the highly pathogenic avian influenza virus H5N1 in a throat swab sample. The RT-PCR results showed equally sensitive, $440 \%$ faster and 2,000-5,000\% cheaper compared to commercially available tests. Wang et al. [55] designed and fabricated a droplet-based micro oscillating flow PCR chip by the silicon microfabrication technique to miniaturize the flow process while maintaining the advantages of fixed temperature conditions. The results 206 (a) capillary

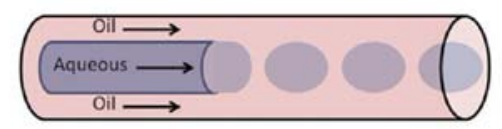

(b) T-Junction

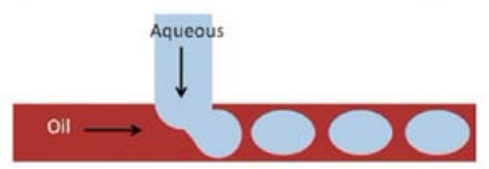

(c) Flow Focusing

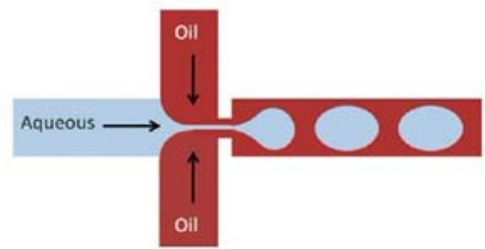

Fig. 6 .Droplet generation strategies: (a) co-flow in a capillary format, (b) T-Junction in a planar chip format, (c) flow focusing in a planar chip format [46].

demonstrated that the chip successfully amplified the HPV-DNA, with a processing time of about $15 \mathrm{~min}$. Mohr et al. [56] investigated some droplet PCR chip design factors including thermal mass, flow rate and thermal resistance. Specially, they focused on the fluid and substrate temperature distribution within the PCR chip and the droplet residence times in critical temperature zones. Some parameters related to PCR amplification efficiency were studied, such as reagent concentration, droplet size and hold time at each temperature step [57].

The droplets, as individual reactors, can contain many DNA templates and be amplified individually. In addition, droplets can be produced at a very high frequency within one experiment, so parallel processing is achievable to produce large data sets and offer higher degree of confidence following analyses [58]. Droplet chips serve as an ideal mean to a future generation of high-throughput droplet PCR [60-64].

A high-throughput microfluidic chip that encapsulates PCR reagents in millions of picoliter droplets in a continuous oil flow was developed and it showed high sensitivity (detection of template concentrations as low as $0.003 \mathrm{pg} / \mu \mathrm{L}$ in $35 \mathrm{~min}$ )[65]. Srisa-Art et al. [66] demonstrated a novel, high-throughput, droplet-based microfluidic assay and allowed for online characterization and detection of droplets (with typical volumes of $300 \mathrm{pl}$ ) at rates in excess of $1 \mathrm{kHz}$. Andrew et al. [67] proposed a high-throughput microfluidic chip, which is capable of generating over 1-million, monodisperse, $50 \mathrm{pl}$ droplets in 2-7 minutes, as shown in Fig. 7. In addition, the chip was integrated rapid droplet generation, thermocycling, and wide-field fluorescence imaging.

Although the development of droplet PCR chips is still in their infancy, they have shown the great potential, particularly for high-throughput PCR [60-64].

\section{SlipChip PCR}

Recently, the team in the University of Chicago 


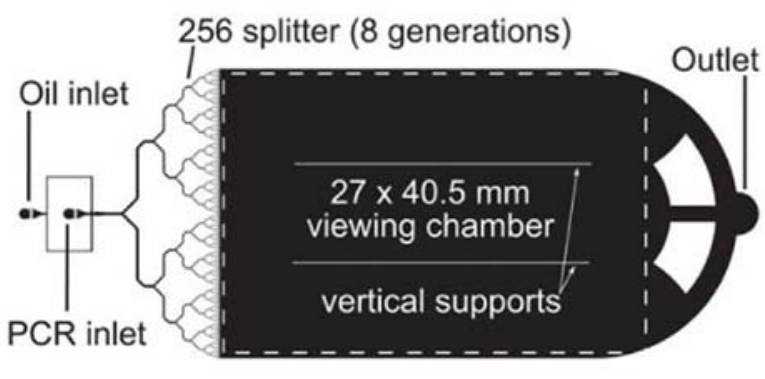

Fig. 7 .High-throughput microfluidic PCR chip [67].

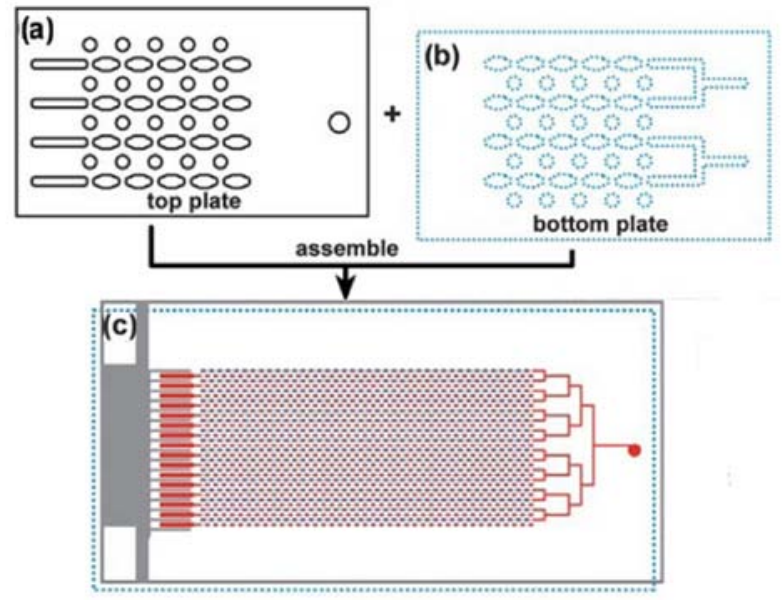

Fig. 8 Schematic drawing of digital SlipChip PCR for: (a) part of the top plate, (b) part of the bottom plate, (c) the entire assembled SlipChip after slipping. [74]

pioneered an ingenious method to perform microfluidic chip without external pumps, valves and other equipment for operation. The system consists of two glass plates with arrays of wells and channels. By moving one plate relative to another plate, reagent and sample can be brought into contact and reaction [68-70]. The SlipChip has been applied to protein crystallization [71, 72], immunoassay [73], nucleic acids analysis [74-76]. They proposed a very simple and inexpensive digital SlipChip PCR that contained 1280 droplets of $2.6 \mathrm{nl}$ each, and was capable of detecting the template DNA at single copy level [74]. Then they developed a highthroughput nanoliter multiplex SlipChip PCR with robust performance and lack of false negatives, false positives, and cross-contamination. The chip was designed to preload one primer pair per reaction compartment and to screen up to 384 different primer pairs with less than 30 $\mathrm{nl}$ of sample per reaction compartment [75].

The SlipChip PCR can perform multiplex detection with different primer pairs loaded in different reaction chambers. Although SlipChip is at an early stage of its development, it offers a new microfluidic platform that opens up new possibilities for the realization of robust chip laboratories [70].

\section{Integrated PCR chip}

The PCR chip has undergone the transition from simple microfluidic components to highly integrated systems.

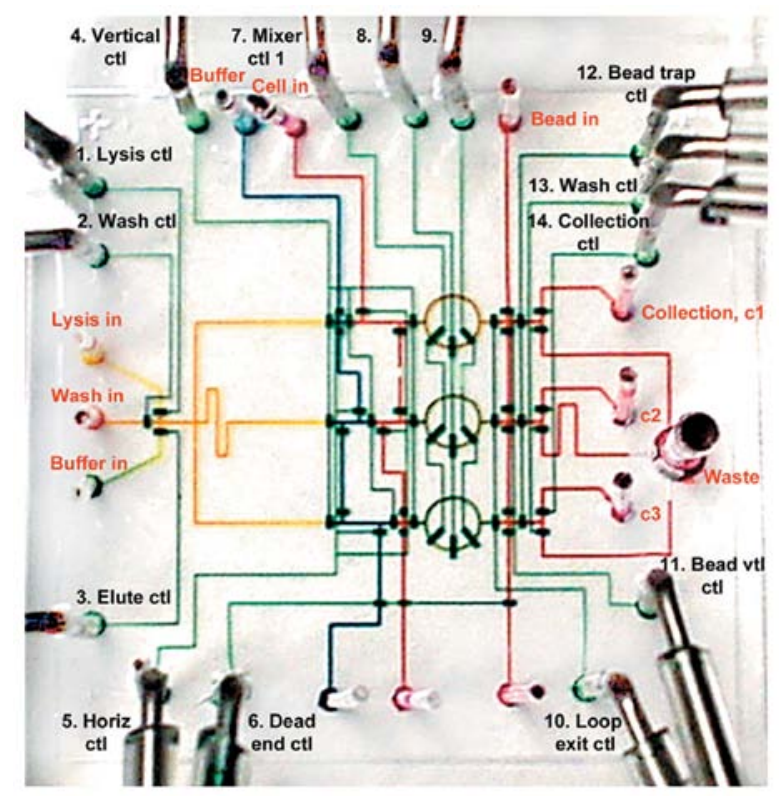

Fig. 9. Integrated PCR chip [80].

An ideal integrated PCR chip can integrate individual microfluidic components, such as cell isolation and capture, cell lysis, DNA/RNA extraction and purification, DNA/RNA amplification, and product detection into a single automated, portable chip with sample-to-answer capability. It is attractive and challenging to realize the integrated chip, especially the low cost, portable, highthroughput integrated chip.

Yuen et al. [77] isolated white blood cells from whole blood by filter section of the microchip and subsequently directly performed PCR. The microchip provides a convenient means to simplify nucleic acid analyses by integrating two key steps: cell isolation and PCR. Ferrance et al. [78] reported a microchip integrated extraction of genomic DNA, IR-mediated PCR amplification and electrophoretic analysis. They used a novel sol-gel matrix to extract of genomic DNA from whole blood, and detected directly by electrophoretic analysis in the chip. Liu et al. [79] developed a self-contained, fully integrated biochip. The chip started with magnetic bead-based target cell capture, cell concentration and purification, and cell lysis, followed by PCR amplification and electrochemical DNA microarray-based detection. The chip provides a cost-effective solution to direct sample-to-answer genetic analysis. Hong et al. [80] developed microfluidic chips for automated nucleic acid purification from small numbers of bacterial or mammalian cells. The chip has 26 access holes, 1 waste hole and 54 valves within $20 \times 20 \mathrm{~mm}^{2}$, as shown in Fig. 9. The chip involves all processes in term of cell isolation, cell lysis, DNA or mRNA purification, and recovery, so any pre- or postsample treatment is not needed. In addition, the chips are capable of processing different samples in parallel, thereby illustrating highthroughput performance.

The PCR product analysis is also important in the integration chip. Some reviews have presented this issue 
http://nanobe.org

in detail $[81,82]$.

One of the main challenges in miniaturization is the integration of functional components to perform several operations without the need for macro apparatus or manual user input. Higher levels of integration can reduce or avoid cross-contamination in a multitude of samples to be run in parallel [83-86].

\section{Conclusions}

The microfluidic PCR chips have undergone extensive development and dramatically changed conventional PCR for DNA amplification. Since the first PCR chip was developed, many microfluidic PCR chips with various characteristics were designed to meet challenges. Chamber stationary PCR chips have high thermal inertia and long thermal-cycling time. Flow-through PCR chips have short cycling time, but result in PCR inhibition and contamination. Convection PCR is predicted to be a promising technology, but challenges still exist in realization of parallel and multiplex convective PCR and integration of convective PCR with other functionalities. To overcome the drawbacks in Flow-through PCR chip, droplet PCR chips are used widely. In addition, they have shown the great potential, particularly for highthroughput PCR, although they are still in the early stage. The ingenious SlipChip PCR provides a method for multiplex detection and opens up new possibilities for the realization of robust chip laboratories. Unfortunately, few microfluidic PCR chips have been commercialized. But there is no doubt that low cost, portable, high-throughout integrated PCR chips will be widely used in the future.

\section{Acknowledgements}

This work was supported by Ministry of Science and Technology of China (2010CB933901), Science and Technology Innovation Fund of SJTU - University of Michigan.

\section{References}

1. Manz A, Graber N, Widmer HM, Miniaturized total chemical analysis systems: A novel concept for chemical sensing. Sens. Actuators B 1990; 1: 244-248.doi: 10.1016/0925-4005(90)80209-I

2. DeMello AJ. Control and detection of chemical reactions in microfluidic systems. Nature 2006; 442: 394-402. doi: 10.1038/ nature 05062

3. Baek SH, Chang WJ, Baek JY, Yoon DS, Bashir R, Lee SW. Dielectrophoretic Technique for Measurement of Chemical and Biological Interactions. Anal Chem 2009; 81: 7737-7742.doi: 10.10 21/ac901211b

4. Huang B, Wu HK, Bhaya D, Grossman A, Granier S, Kobilka BK, Zare RN. Counting low- copy number proteins in a single cell. Science2007; 315: 81-84. doi: 10.1126/science.1133992

5. Zare RN, Kim S. Microfluidic platforms for single-cell analysis. Annu. Rev. Biomed. Eng. 2010; 12:187-201. doi: 10.1146/annurevbioeng-070909-105238

6. Sato K, Mawatari K, Kitamori T. Microchip-based cell analysis and clinical diagnosis system.Lab Chip 2008; 8: 1992-1998. doi: 10.1039/ B814098G

7. Dittrich PS, Manz A. Lab-on-a-chip: microfluidics in drug discovery. Nat Rev Drug Discov. 2006; 5: 210-218. doi: 10.1038/nrd1985

8. Gardeniers JGE, van den Berg A. Lab-on-a-chip systems for biomedical and environmental monitoring. Anal Bioanal Chem 2004; 378: 1700-1703.doi: 10.1007/s00216-003-2435-7

9. Saiki RK, Scharf F, Faloona F, Mullis KB, Horn GT, Erlich HA, Arnheim N. Enzymatic amplification of beta-globin genomic sequences and restriction site analysis for diagnosis of sickle cell anemia. Science, 1985; 230: 1350-1354. doi: 10.1126/science. 2999980

10.Northrup MA, Ching MT, White RM, Watson RT. DNA amplification in a microfabricated reaction chamber. In tranducer'93, seventh international conference on solid state Sens Actuators, Yokohama, Japan. ISBN:4-9900247-2-9. 1993; 924-926.

11. Kricka LJ, Wilding P. Microchip PCR. Anal Bioanal Chem 2003;37 7: 820- 825. doi: 10.1007/s00216-003-2144-2

12.Zhang CS, Xing D. Miniaturized PCR chips for nucleic acid amplification and analysis: latest advances and future trends. Nucleic Acids Res.2007; 35: 4223-4237. doi: 10.1093/nar/gkm389

13.Ong SE, Zhang S, Du HJ, Fu YQ. Fundamental principles and applications of microfluidic systems. Frontiers Biosci. 2008;13: 2757 -2773. doi: $10.2741 / 2883$

14.Zhang YH, Ozdemir P. Microfluidic DNA amplification-A review. Anal. Chim. Acta 2009; 638: 115-125. doi: 10.1016/j.aca.2009.02.038

15.Shin YS, Cho K, Lim SH, Chung S, Park SJ, Chung C, Han DC, Chang JK. PDMS-based micro PCR chip with parylene coating. J. Micromech. Microeng. 2003; 13: 768-774. doi: 10.1088/0960$1317 / 13 / 5 / 332$

16. El-Ali J, Perch-Nielsen IR, Poulsen CR, Bang DD, Telleman P, Wolff A. Simulation and experimental validation of a SU-8 based PCR thermocycler chip with integrated heaters and temperature sensor. Sens. Actuators A 2004; 110: 3-10. doi:10.1016jsna.2003.09.022

17.Pasquardini L, Potrich C, Quaglio M, Lamberti A, Guastella S, Lunelli L, Cocuzza M, Vanzetti L,Pirri CF, Pederzolli C. Solid phase DNA extractionon PDMS and direct amplification. Lab Chip 2011; 11: 4029-4035.doi: 10.1039/c1lc20371a

18.Nagai H, Murakami Y, Morita Y, Yokoyama K, Tamiya E. Development of a microchamber array for picoliter PCR. Anal. Chem.2001; 73:1043-1047. doi: 10.1021/ac000648u

19. Matsubara Y, Kerman K, Kobayashi M,Yamanura S, Morita Y, Tamiya E. Microchamber array based DNA quantification and specific sequence detection from a single copy via PCR in nanoliter volumes. Biosens. Bioelectron. 2005; 20:1482-1490. doi: 10.1016/ j.bios.2004.07.002

20. Zou Q, Miao Y, Chen Y, Sridhar U, Chong CS, Chai T, et al. Microassembled multi-chamber thermal cycler for low-cost reaction chip thermal multiplexing. Sens. Actuators A 2002;102: 114- 121. doi: 10.1016/S0924-4247(02)00384-9

21. Cady NC, Stelick S, Kunnavakkam MV, Batt CA. Real-time PCR detectionof Listeria monocytogenes using anintegrated microfluidics platform. Sens. Actuators B.2005; 107: 332-341. doi: 10.1016/ j.snb. 2004.10.022

22. Qiu XB, Mauk MG, Chen DF, Liu CC, Bau HH.A large volume, portable, real-time PCR reactor. Lab Chip 2010; 10: 3170-3177. doi: $10.1039 / \mathrm{c} 01 \mathrm{c} 00038 \mathrm{~h}$

23 .Daniel JH, Iqbal S, Millington RB, Moore DF, Lowe CR, Leslie DL, et al. Silicon microchambers for DNA amplification. Sen. Actuators A 1998;71: 81-88. doi: 10.1016/S0924-4247(98)00158-7

24. Trung NB, Saito M, Takabayashi H, Pham HV, Tamiya E, Takamura, Y. Multi-chamber PCR chip with simple liquid introduction utilizing the gas permeability of polydimethylsiloxane. Sens. Actuators B.2010; 149: 284-290. doi: 10.1016/j.snb.2010.06.013

25. Nagai H, Murakami Y, Yokoyama K, Tamiya E. High-throughput PCR in silicon based microchamber array. Biosens. Bioelectron. 2001, 16, 1015. 2001; 16: 1015-1019. doi: 10.1016/S0956-5663(01) 00248-2

26.Kopp MU, de Mello AJ, Manz A. Chemical Amplification: Continuous-Flow PCR on a Chip. Science 1998; 280: 1046-1048. doi: 10.1126/science.280.5366.1046

27.Liu J, Enzelberger M, Quake S. A nanoliter rotary device for polymerase chain reaction Eletrophoresis 2002; 23: 1531-1536. doi:10.1002/1522-2683(200205)23:10<1531::AID-ELPS1531>3.0. $\mathrm{CO} ; 2-\mathrm{D}$

28. Wu WM, Lee NY. Three-dimensional on-chip continuous-flow 
polymerase chain reaction employing a single heater. Anal. Bioanal. Chem. 2011; 400: 2053-2060. doi: 10.1007/s00216-0114947-x

29.Fu LM, Yang RJ, Lee GB, Liu HH. Electrokinetic injection techniques in microfluidic chips. Anal. Chem. 2002; 74: 5084-5091. doi: $10.1021 / \mathrm{ac} 025821 \mathrm{w}$

30.Patankar NA, Hu HH. Numerical simulation of electroosmotic flow. Anal. Chem. 1998; 70: 1870-1881. doi: 10.1021/ac970846u

31.Gui L, Ren CL. Numeric simulation of heat transfer and electrokinetic flow in an electroosmosis-based continuous flow PCR chip. Anal. Chem. 2006;78: 6215-6222. doi: 10.1021/ac060553d

32.Furutani S, Nagai H, Takamura Y, Kubo I. Compact disk (CD)shaped device for single cell isolation and PCR of a specific gene in the isolated cell. Anal. Bioanal. Chem. 2010; 398: 2997-3004. doi: 10.1007/s00216-010-4205-7

33.Focke M, Stumpf F, Faltin B, Reith P, Bamarni D, Wadle S, et al. Microstructuring of polymer films for sensitive genotyping by realtime PCR on a centrifugal microfluidic platform. Lab Chip 2010; 10: 2519-2526. doi: 10.1039/c004954a

34. Sun Y, KwokYC, Nguyen NT. A circular ferrofluid driven microchip for rapid polymerase chain reaction. Lab Chip 2007; 7: 1012-1017. doi: 10.1039/b700575j

35.Sun Y, Kwok YC, Lee PFP, Nguyen NT. Rapid amplification of genetically modified organisms using a circular ferrofluid-driven PCR microchip. Anal. Bioanal. Chem. 2009; 394: 1505-1508.doi: 10.1007/s00216-009-2808-7

36.Gonzalez A, Grimes R, Walsh EJ, Dalton T, Davies M. Interaction of quantitative PCR components with polymeric surfaces. Biomed. Microdevices 2007; 9: 261-266. doi: 10.1007/s10544-006-9030-6

37. Kolari K, Satokari R, Kataja K, Stenman J, Hokkanen A. Real-time analysis of PCR inhibition on microfluidic materials. Sens. Actuators B 2008; 128: 442-449. doi: 10.1016/j.snb.2007.06.034

38.Krishnan M, Ugaz VM, Burns MA. PCR in a RayleighBénard convection cell. Science 2003; 298:793. doi: 10.1126/ science.298.5594.793

39. Yao DJ, Chen JR, Ju WT. Micro-Rayleigh-Benard convection polymerase chain reaction system. J. Micro/Nanolith. MEMS MOEMS 2007; 6: 043007. doi: 10.1117/1.28054523

40.Chung KH, Choi YH, Jung MY. Natural Convection PCR in a Disposable Polymer Chip. IEEE SENSORS 2009; 1-3: 1159-1162.

41. Zhang C, Xu J, Ma W, Zheng W. PCR microfluidic devices for DNA amplification. Biotechnol. Adv. 2006; 24: 243-284. doi: 10.1016/ j.biotechadv.2005.10.002

42.Braun D. PCR by thermal convection. Modern Physics Letters B 2004; 18: 775- 784. doi: 10.1142/S0217984904007049

43.Schneegass I, Brautigam R, Kohler JM.Miniaturized flow-through PCR with different template types in a silicon chip thermocycler. Lab Chip 2001; 1: 42-49. doi: 10.1039/b103846j

44. Fukuba T, Yamamoto T, NaganumaT, Fujii T. Microfabricated flowthrough device for DNA amplification-towards in situ gene analysis. Chem. Eng. J. 2004; 101: 151-156. doi: 10.1016/j.cej.2003.11.016

45. Kim JA, Lee JY, Seong S, Cha SH, Lee SH, Kim JJ, Park TH. Fabrication and characterization of a PDMS-glass hybrid continuous-flow PCR chip. Biochem. Eng. J. 2006; 29: 91-97. doi: 10.1016/j.bej.2005.02.032

46. Solvas XCI, deMello A. Droplet microfluidics: recent developments and future applications. Chem. Commun. 2011; 47:1936-1942. doi: $10.1039 / \mathrm{c} 0 \mathrm{cc} 02474 \mathrm{k}$

47.Günther A, Jhunjhunwala M, Thalmann M,Schmidt MA, Jensen KF. Micromixing of miscible liquids in segmented gas-liquid flow. Langmuir. 2005; 211: 547-1555. doi: 10.1021/la0482406

48.Link DR, Grasland-Mongrain E, Duri A, Sarrazin F, Cheng Z, Cristobal G, Weitz DA. Electric Control of Droplets in Microfluidic Devices. Angew. Chem. Int. Ed. 2006; 118: 2618-2622. doi: 10.1002/ anie. 200503540

49. Teh SY, Lin R, Hung LH, Lee AP. Droplet microfluidics. Lab Chip 2008; 8: 198-220. doi: 10.1039/b715524g

50.Fair RB. Digital microfluidics: is a true lab-on-a-chip possible? Microfluid. Nanofluid.2007; 3:245-281. doi: 10.1007/s10404-0070161-8

51. Niu X, Zhang M, Peng S, Wen W, Sheng P. Real-time detection, control, and sorting of microfluidic droplets. Biomicrofluidics 2007; 1: 044101-044112. doi: 10.1063/1.2795392

52.Shi W, Qin J, Ye N, Lin B. Droplet-based microfluidic system for individual Caenorhabditis elegans assay. Lab Chip 2008; 8: 14321435. doi: 10.1039/b808753a

53. Song H, Tice JD, Ismagilov RF, A microfluidic system for controlling reaction networks in time. Angew. Chem. 2003; 115:79296.doi: 10.1002 / ange. 200390172

54. Pipper J, Inoue M, Ng, LFP, Neuzil P, Zhang Y, Novak L. Catching bird flu in a droplet. Nat. Med. 2007; 13: 1259-1263. doi: 10.1038/ nm1634

55.Wang W, Li ZX, Luo R, Shu-Hai Lu SH, Xu AD, Yang YJ. Dropletbased micro oscillating-flow PCR chip. J. Micromech. Microeng. 2005;15: 1369-1377. doi: 10.1088/0960-1317/15/8/001

56. Mohr S, Zhang YH, Macaskill A, Day PJR, Barber RW, Goddard $\mathrm{NJ}$, et al. Numerical and experimental study of a droplet-based PCR chip. Microfluid. Nanofluid. 2007; 3: 611-621. doi: 10.1007/s10404007-0153-8

57.Wang F, Burns MA. Performance of nanoliter-sized droplet-based microfluidic PCR. Biomed. Microdevices 2009; 11:1071-1080.doi: 10.1007/s10544-009-9324-6

58.Trietsch SJ, Hankemeier T, van der Linden HJ. Lab-on-a-chip technologies for massive parallel data generation in the life sciences: A review. Chemometr. Intell. Lab.Syst. 2011; 108: 64-75. doi:10.10 16/ j.chemolab.2011.03.005

60. Schaerli Y, Hollfelder F. The potential of microfluidic water-in-oil droplets in experimental biology. Mol. BioSyst. 2009;5: 1392-1404. doi: 10.1039/b907578j

61.Leamon JH, Link DR, Egholm M, Rothberg JM.Overview: methods and applications for droplet compartmentalization of biology. Nat. Methods 2006; 3: 541-543. doi: 10.1038/nmeth0706-541

62. Huebner A, Sharma S, Srisa-Art M, Hollfelder F, Edel JB, deMello AJ. Microdroplets: A sea of applications? Lab Chip 2008; 8: 1244 1254. doi: $10.1039 / \mathrm{b} 806405 \mathrm{a}$

63. Taly V, Kelly BT, Griffiths AD. Droplets as Microreactors for HighThroughput Biology. ChemBioChem 2007; 8: 263 - 272. doi: 10.10 02/cbic. 200600425

64. B aret JC, Tally V, Ryckelynck M, Merten CA, Griffiths AD. roplets and emulsions: very high-throughput screening in biology. Med. Sci. 2009; 25: 627-632. doi: 10.1051/medsci/2009256-7627

65.Kiss MM, Ortoleva-Donnelly L, Beer NR, Warner J, Bailey CG, Colston BW, et al. High-throughput quantitative polymerase chain reaction in picoliter droplets. Anal. Chem.2008; 80: 8975-8981. doi: $10.1021 / \mathrm{ac} 801276 \mathrm{c}$

66.Srisa-Art M, deMello AJ, Edel JB. High-throughput DNA droplet assays using picoliter reactor volumes. Anal. Chem. 2007; 79: 66826689. doi: $10.1021 / \mathrm{ac} 070987 \mathrm{o}$

67.Hatch AC, Fisher JS, Tovar AR, Hsieh AT, Lin R, Pentoney SL, et al. 1-Million droplet array with wide-field fluorescence imaging for digital PCR. Lab Chip 2011; 11: 3838-3845. doi: 10.1039/c1lc20561g

68. Du WB, Li L, Nichols KP, Ismagilov RF. SlipChip. Lab Chip 2009; 9:2286-2292. doi: 10.1039/b908978k

69.Li L, Du WB, Ismagilov RF. User-Loaded SlipChip for EquipmentFree Multiplexed Nanoliter-Scale Experiments. J. Am. Chem. Soc. 2010; 132: 106-111. doi: 10.1021/ja908555n

70.Belder D, Screening in One Sweep using the Slipchip. Angew. Chem. Int. Ed. 2010; 49: 6484-6486. doi: 10.1002/anie.201002059

71. Li L, Du WB, Ismagilov RF. Multiparameter Screening on SlipChip Used for Nanoliter Protein Crystallization Combining Free Interface Diffusion and Microbatch Methods. J. Am. Chem. Soc. 2010; 132: 112-119. doi: 10.1021/ja908558m

72.Li L, Ismagilov RF. Protein Crystallization Using Microfluidic Technologies Based on Valves, Droplets, and SlipChip. Annu. Rev. Biophys. 2010; 39:139-158. doi: 10.1146/annurev. biophys.050708.133630

73.Liu WS, Chen DL, Du WB, Nichols KP, Ismagilov RF.SlipChip for Immunoassays in Nanoliter Volumes. Anal. Chem. 2010: 82: 3276-3282. doi: 10.1021/ ac100044c74. Shen F, Du WB, Kreutz JE, Fok A, Ismagilov RF. Digital PCR on a SlipChip. Lab Chip 2010; 10: 2666-2672. doi: 10.1039/c004521g 


\section{Nano Biomed. Eng.}

http://nanobe.org

75.Shen F, Du WB, Davydova EK, Karymov MA, Pandey J, Ismagilov RF. Nanoliter Multiplex PCR Arrays on a SlipChip. Anal. Chem. 2010; 82: 4606-4612. doi: 10.1021/ac1007249

76.Shen F, Davydova EK, Du WB, Kreutz JE, Piepenburg O, Ismagilov RF. Digital Isothermal Quantification of Nucleic Acids via Simultaneous Chemical Initiation of Recombinase Polymerase Amplification Reactions on SlipChip. Anal. Chem. 2011; 83: 35333540. doi: $10.1021 / \mathrm{ac} 200247 \mathrm{e}$

77. Yuen PK, Kricka LJ, Fortina P, Panaro NJ, Sakazume T, Wilding P. Microchip module for blood sample preparation and nucleic acid amplification reactions.Genome Res. 2001; 11:405-412. doi: 10.110 1/gr. 155301

78. Ferrance JP, Wu QR, Giordano B, Hernande C, Kwok Y, Snow, K, et al. Developments toward a complete micro-total analysis system for Duchenne muscular dystrophy diagnosis. Analytica Chimica Acta 2003; 500: 223-236. doi: 10.1016/j.aca.2003.08. 067

79.Liu RH, Yang JN, Lenigk R, Bonanno J, Grodzinski P. Selfcontained, fully integrated biochip for sample preparation, polymerase chain reaction amplification, and DNA microarray detection Anal. Chem. 2004; 76: 1824-1831. doi: 10.1021/ac03530 29

80.Hong JW, Studer V, Hang G, Anderson WF, Quake SR. A nanoliterscale nucleic acid processor with parallel architecture. Nat.
Biotechnol. 2004; 22: 435-439. doi: 10.1038/nbt951

81.Chen L, Manz A, Day PJR. Total nucleic acid analysis integrated on microfluidic devices. Lab Chip 2007; 7: 1413-1423. doi: 10.1039/ b708362a

82. Lui C, Cady NC, Batt CA. Nucleic acid-based detection of bacterial pathogens using integrated microfluidic platform systems. Sensors 2009; 9:3713-3744; doi: 10.3390/s90503713

83.Zhang CS, Xing D, Li YY. Micropumps,microvalves, and micromixers within PCR microfluidic. chips: Advances and trends. Biotech. Adv. 2007; 25: 483-514. doi: 10.1016/j.biotechadv.2007.05.0 03

84.Laser DJ, Santiago JG. A review of micropumps.J.Micromech. Microeng. 2004; 14:R35-R64. doi: 10.1088/0960-1317/14/6/R01

85.Nguyen NT, Wu ZG. Micromixers-a review. J.Micromech. Microeng. 2005; 15: R1-R16. doi: 10.1088/0960-1317/15/2/R01

86.Oh KW, Ahn CH. A review of microvalves. J. Micromech. Microeng. 2006; 16: R13-R39. doi: 10.1088/0960-1317/16/5/R01

Copyright:(c) $2011 \mathrm{~J}$. Chen, et al. This is an open-access article distributed under the terms of the Creative Commons Attribution License, which permits unrestricted use, distribution, and reproduction in any medium, provided the original author and source are credited. 